\title{
Repetibilidade e respostas de características morfofisiológicas e produtivas de capim-elefante de porte baixo sob pastejo
}

\author{
Bruno Leal Viana(1), Alexandre Carneiro Leão de Mello(1), Mário de Andrade Lira(1), \\ José Carlos Batista Dubeux Júnior ${ }^{(1)}$, Mércia Virgínia Ferreira dos Santos ${ }^{(1)}$, \\ Márcio Vieira da Cunha ${ }^{(2)}$ e Geane Dias Gonçalves Ferreira( ${ }^{(3)}$
}

\begin{abstract}
(1)Universidade Federal Rural de Pernambuco (UFRPE), Departamento de Zootecnia, Avenida Dom Manuel de Medeiros, s/no, Dois Irmãos, CEP 52171-900 Recife, PE. E-mail: brunoviana.ufrpe@yahoo.com.br, mello@dz.ufrpe.br, mariolira@terra.com.br, dubeux@dz.ufrpe.br, mercia@dz.ufrpe.br (2)UFRPE, Unidade Acadêmica de Serra Talhada, Fazenda Saco, s/no, Caixa Postal 063, CEP 56903-970 Serra Talhada, PE. E-mail: marciovc@msn.com.br (3)UFRPE, Unidade Acadêmica de Garanhuns, Avenida Bom Pastor, s/nº, Boa Vista, CEP 55296-901 Garanhuns, PE. E-mail: geane@uag.ufrpe.br
\end{abstract}

Resumo - O objetivo deste trabalho foi estimar os coeficientes de repetibilidade, de determinação $\left(\mathrm{R}^{2}\right)$ e o número mínimo de medições necessárias para predizer o valor real de variáveis morfofisiológicas e produtivas, bem como as respostas do capim-elefante de porte baixo ao pastejo com ovinos. O experimento foi realizado em blocos ao acaso, com cinco tratamentos - Taiwan A-146 2.27, Taiwan A-146 2.37, Taiwan A-146 2.114, Merker México MX 6.31 e Mott - e quatro repetições, ao longo de cinco ciclos de pastejo entre setembro de 2008 e abril de 2009. Foram avaliados a altura média de plantas, o índice de área foliar (IAF), a interceptação luminosa (IL), os ângulos foliares médios (AFM), o acúmulo de forragem (AF) e a taxa de acúmulo de forragem (TAF). Para as variáveis IAF, IL e altura média de plantas, nos ciclos longos, foi necessária apenas uma medição $\left(\mathrm{R}^{2}=80 \%\right)$ para classificá-las como de mais fácil predição em clones de capim-elefante. Avaliações de AF e de TAF necessitam de períodos experimentais mais longos, para maior confiabilidade na estimativa dessas variáveis resposta. Dosséis de capim-elefante de porte baixo interceptam maior quantidade de radiação incidente, quanto maior for a altura média das plantas e o IAF.

Termos para indexação: Pennisetum purpureum, ângulos foliares, capim-elefante anão, índice de área foliar, interceptação luminosa.

\section{Repeatability of morphophysiological and yield characteristics and response of dwarf elephant grass under grazing}

\begin{abstract}
The objective of this study was to estimate the coefficients of repeatability and determination $\left(\mathrm{R}^{2}\right)$ and the minimum number of measurements necessary to predict the real value of morphophysiological and yield variables, as well as the responses to sheep-grazing of dwarf elephant grass pasture. The experiment was carried out in a randomized block design with five treatments - Taiwan A-146 2.27, Taiwan A-146 2.37, Taiwan A-146 2.114, Merker México MX 6.31 and Mott - and four replicates, over five grazing cycles, between September 2008 and April 2009. Mean sward height, leaf area index (LAI), light interception (LI), mean leaf angles (MLA), silage accumulation (SA) and silage accumulation rate (SAR) were evaluated. For the variables LAI, IL and mean sward height of plants, in long cycles, only one measurement was necessary $\left(\mathrm{R}^{2}=80 \%\right)$ to place them among the most predictable characteristics in the evaluation of elephant grass clones. Assessments for SA and SAR need longer experimental periods for greater reliability in the estimation of response variables. In dwarf elephant grass, light interception increases with sward height and LAI.
\end{abstract}

Index terms: Pennisetum purpureum, leaf angle, dwarf elephant grass, leaf area index, light interception.

\section{Introdução}

O capim-elefante (Pennisetum purpureum Schumach.), além de ser uma das espécies forrageiras tropicais com maior eficiência no aproveitamento da radiação solar, apresenta alta eficiência na utilização de água e nutrientes, o que resulta em elevada capacidade de produção de forragem (Jacques, 1994; Campos, 1999).

Em razão do elevado acúmulo de massa de matéria seca, o cultivo das espécies do gênero Pennisetum para fins forrageiros tem despertado o interesse de pecuaristas e pesquisadores, sobretudo para a formação

Pesq. agropec. bras., Brasília, v.44, n.12, p.1731-1738, dez. 2009 
de capineiras. Apesar do potencial para utilização em pastejo, a adoção desse sistema no Brasil ainda é incipiente, seja pela dificuldade de manejo, seja pelo elevado custo de manutenção, sobretudo pela alta exigência em fertilidade do solo, que eleva os gastos com adubação. Entretanto, essa baixa utilização em pastejo das cultivares de capim-elefante de porte alto não ocorre com o capim-elefante de porte baixo que, em diversas avaliações, tem demonstrado elevado desempenho na alimentação animal (Flores et al., 1993; Silva et al., 1994; Almeida et al., 2000b).

Contudo, são raros os relatos de experimentos sobre capim-elefante submetido ao pastejo de pequenos ruminantes. Graças à qualidade da forragem produzida, aliada ao potencial de acúmulo de forragem, o uso de cultivares de porte baixo pode representar importante alternativa para sistemas de produção de pequenos ruminantes, com o objetivo de aumento da produtividade animal e redução de custos de alimentação dos animais. Resende et al. (2002) demonstraram a possibilidade dessa alternativa para pequenos ruminantes e avaliaram a melhor altura de pastejo para reduzir a decapitação dos meristemas apicais, localizados próximos ao solo, e conferir alta persistência ao pastejo.

A análise de repetibilidade permite o estudo da correlação entre medidas consecutivas em um mesmo indivíduo (Cruz \& Regazzi, 1997). Altos valores de repetibilidade de quaisquer características indicam que é possível predizer o valor real dos indivíduos, com base em determinado número de medições. Segundo Falconer (1981), com medições subsequentes de uma mesma característica em um indivíduo, a variância fenotípica pode ser parcelada, o que permite quantificar o ganho em precisão e, também, esclarecer a natureza da variação causada pelo ambiente.

Por meio das estimativas dos coeficientes de repetibilidade, é possível determinar quantas medições devem ser realizadas em cada indivíduo, para que a seleção fenotípica entre os genótipos seja feita com eficiência (Cruz \& Regazzi, 1997; Pereira et al., 2002). Assim, é necessária a avaliação das respostas de cultivares de capim-elefante de porte baixo ao pastejo por pequenos ruminantes, para se obterem informações confiáveis e com um mínimo de custo de mão de obra.

O objetivo deste trabalho foi estimar os coeficientes de repetibilidade e de determinação e o número mínimo de medições necessárias para predizer o valor real, pela análise dos componentes principais, para variáveis morfofisiológicas e produtivas, bem como as respostas do capim-elefante de porte baixo ao pastejo de ovinos.

\section{Material e Métodos}

O experimento foi realizado na Estação Experimental do Instituto Agronômico de Pernambuco (IPA), no Município de Itambé, Zona da Mata Seca de Pernambuco, entre setembro de 2008 e abril de 2009. No local, a precipitação média anual é de aproximadamente $1.200 \mathrm{~mm}$ (Governo de Pernambuco, 2003), a temperatura média anual é de $26^{\circ} \mathrm{C}$ e a altitude é de $190 \mathrm{~m}$. Durante o período experimental, foi registrada a precipitação acumulada de $798,6 \mathrm{~mm}$, com média mensal de $88,7 \mathrm{~mm}$.

O solo da área - classificado como Argissolo Vermelho-Amarelo de textura franco-argilo-arenosa (Santos et al., 2006), com relevo suave-ondulado teve suas características químicas avaliadas em março de 2007. A análise química do solo na camada $0-20 \mathrm{~cm}$ de profundidade apresentou os seguintes resultados: $\mathrm{pH}, \quad 5,5$ (água); $\mathrm{P}, \quad 10,8 \mathrm{mg} \mathrm{\textrm {dm } ^ { - 3 }}$ (Mehlich-1); $\mathrm{K}, 0,22 \mathrm{cmol}_{\mathrm{c}} \mathrm{dm}^{-3} ; \mathrm{Al}, 0,4 \mathrm{cmol}_{\mathrm{c}} \mathrm{dm}^{-3} ; \mathrm{Ca}+\mathrm{Mg}$, 2,2 $\mathrm{cmol}_{\mathrm{c}} \mathrm{dm}^{-3}$; CTC, 5,3 $\mathrm{cmol}_{\mathrm{c}} \mathrm{dm}^{-3}$; MO, $19 \mathrm{~g} \mathrm{~kg}^{-1}$; e saturação por bases, $46 \%$. O solo da área experimental foi preparado mecanicamente por meio de aração, gradagem e abertura dos sulcos para o plantio.

Os tratamentos consistiram de cinco genótipos de capim-elefante de porte baixo (progênies 2.27, $2.37 \mathrm{e}$ 2.114 do clone Taiwan A-146, progênie 6.31 do clone Merker México MX e do clone Mott), arranjados em delineamento em blocos ao acaso, com quatro repetições. Os clones do grupo Taiwan, assim como o do Merker México MX, são materiais gerados no programa de melhoramento genético de capim-elefante do acordo UFRPE/IPA. Mott é uma variedade de porte baixo, originada na Flórida, EUA, introduzida no Brasil no início da década de 1980, e vem sendo utilizada em pesquisas sobre pastejo (Flores et al., 1993; Silva et al., 1994; Almeida et al., 2000a, 2000b).

Os genótipos foram implantados em parcelas de $25 \mathrm{~m}^{2}(5 \times 5 \mathrm{~m})$ de área total, com $9 \mathrm{~m}^{2}(3 \times 3 \mathrm{~m})$ de área útil. Em 16 de julho de 2007, foram plantados colmos inteiros, em sulcos espaçados em $1 \mathrm{~m}$, previamente adubados com $120 \mathrm{~kg} \mathrm{ha}^{-1}$ de $\mathrm{P}_{2} \mathrm{O}_{5}$ e $80 \mathrm{~kg} \mathrm{ha}^{-1}$ de $\mathrm{K}_{2} \mathrm{O}$. Após a adubação, as parcelas foram submetidas a cinco cortes experimentais que precederam o início do experimento. 
As avaliações foram realizadas em cinco ciclos de pastejo, iniciados em setembro de 2008 e finalizados em abril de 2009. Foram utilizados 25 ovinos da raça Santa Inês, com peso vivo médio inicial de $42 \mathrm{~kg}$, como animais pastejadores em "mob grazing", para se obter altura de resíduo de $0,3 \mathrm{~m}$. Os clones de capim-elefante foram manejados sob lotação animal intermitente, com período de descanso de 32 dias e três dias de pastejo para os ciclos um, dois e cinco (ciclos curtos), e 64 dias de descanso e dois de pastejo para os ciclos três e quatro (ciclos longos). Os distintos períodos de descanso foram determinados pela altura média das plantas, aos 32 dias de rebrota. Quando essa variável não atingiu a altura mínima de $0,5 \mathrm{~m}$, os períodos de descanso passaram a ser de 64 dias. O critério utilizado para os dias de permanência dos animais nos piquetes foi a altura média de resíduo desejada. Após os ciclos de pastejo curtos, foram realizadas adubações com $50 \mathrm{~kg} \mathrm{ha}^{-1}$ de $\mathrm{N}$ na forma de ureia.

Antes da entrada dos animais, foram medidos o índice de área foliar (IAF), a interceptação luminosa (IL), os ângulos foliares médios (AFM), a altura média de plantas, o acúmulo (AF) e as taxas de acúmulo de forragem (TAF). Para as estimativas do IAF, IL e AFM, utilizou-se um analisador de dossel LI-COR, modelo LAI 2000 (LI-COR, Lincoln, Nebraska, EUA), que permite amostragens rápidas e não destrutivas (Welles \& Norman, 1991). Foram tomadas três medições na área útil das parcelas, tendo-se buscado pontos representativos da condição média de cada parcela experimental, no total de três leituras acima e seis leituras abaixo do dossel. As leituras abaixo do dossel foram realizadas a aproximadamente $10 \mathrm{~cm}$ acima do nível do solo e a $5 \mathrm{~cm}$ da base das touceiras.

Para AF e TAF, foram realizadas estimativas de massa de matéria seca da forragem verde (MSV), obtidas pela utilização do método direto, por meio do corte da forragem verde contida em uma moldura de $0,5 \mathrm{~m}^{2}$ $(0,5 \times 1 \mathrm{~m})$ por parcela, a $5 \mathrm{~cm}$ do nível do solo. Após o corte, a forragem fresca foi pesada, subamostrada, novamente pesada e levada para pré-secagem a $65^{\circ} \mathrm{C}$ por 72 horas, em estufa de circulação forçada de ar, e pesada para a obtenção da massa de matéria seca.

$\mathrm{O}$ acúmulo de forragem (AF) $\left(\mathrm{kg} \mathrm{ha}^{-1}\right.$ de MS por ciclo) foi determinado pela subtração de MSV, do pós-pastejo do ciclo n-1, da MSV do pré-pastejo do ciclo n. Os valores de AF foram divididos pelo número de dias de descanso em cada ciclo de pastejo, tendo-se obtido, assim, os valores de TAF ( $\mathrm{kg} \mathrm{ha}^{-1}$ de MS por dia).
A altura média do dossel foi estimada por meio de cinco medições por parcela, tendo-se considerado a distância entre o solo e a inflexão da folha mais alta da touceira, com o auxílio de uma trena.

Os coeficientes de repetibilidade (r) e determinação $\left(\mathrm{R}^{2}\right)$ foram estimados pelo método dos componentes principais, obtidos a partir da matriz de covariância para as sucessivas medições, conforme Shimoya et al. (2002) e Lédo et al. (2008). Assim, o coeficiente $r$ foi obtido pela fórmula: $r=\left(\lambda_{1}-1\right) /(\eta-1)$,

em que: $\lambda$ é o maior autovalor, associado ao autovetor cujos elementos apresentam o mesmo sinal emagnitudes próximas, obtido de $\hat{\mathrm{R}}$, que é a matriz de correlações obtidas a partir dos dados observados. O coeficiente de determinação é dado por:

$\mathrm{R}^{2}=(\eta \mathrm{r}) /[1+\mathrm{r}(\eta-1)]$

em que $\eta$ é o número de cortes e $r$ é coeficiente de repetibilidade.

Foram estimados, também, os números de medidas necessárias para predizer o valor real das variáveis resposta, considerando-se $\mathrm{R}^{2}$ pré-estabelecido de 0,80 (Cruz \& Regazzi, 1997), pela fórmula:

$\eta=R^{2}(1-r) /\left(1-R^{2}\right) r$,

em que: ๆé o número mínimo de medições para predição do valor real; $\mathrm{R}^{2}$ é o coeficiente de determinação; e r é o coeficiente de repetibilidade. As análises estatísticas de repetibilidade foram realizadas por meio do programa Genes (Cruz, 2007).

Para as variáveis resposta que obtiveram, em sua maioria, número de medidas necessárias para predizer o valor real igual ou inferior a cinco, procedeu-se, ainda, à análise de variância, por meio do comando "REPEATED" do procedimento GLM do programa SAS (SAS Institute, 2001), em delineamento de blocos ao acaso, com medidas repetidas no tempo, conforme Vieira et al. (2007). Antes da realização dessa análise para os ciclos de pastejo curtos, procedeu-se ao teste de esfericidade de Mauchly (1940), para verificar se a matriz de covariâncias atendia à condição $\mathrm{H}-\mathrm{F}$ (Huynh-Feldt). A análise multivariada de medidas repetidas no tempo foi utilizada, quando o teste de esfericidade foi significativo a $1 \%$ de probabilidade. Para a comparação das médias, foi utilizado o teste de Tukey, a 5\% de probabilidade.

Todas as análises foram realizadas considerando-se duas situações distintas: três ciclos com períodos de rebrota curtos de 32 dias, e dois ciclos com períodos de rebrota longos de 64 dias. 


\section{Resultados e Discussão}

Os coeficientes de repetibilidade (r) nos ciclos curtos de 32 dias oscilaram entre 0,66 e 0,80, para IL e altura média de plantas, respectivamente (Tabela 1). Nos ciclos longos de 64 dias, foram observados os maiores valores de $r$, em que a variável AFM apresentou o maior valor $(\mathrm{r}=0,90)$, e altura média de plantas apresentou o menor valor $(r=0,80)$. Segundo Shimoya et al. (2002), valores de $r$ acima de 0,80 são considerados satisfatórios quando o coeficiente de determinação é igual ou superior a esse valor. Para a altura média de plantas, foi estimado $\mathrm{R}^{2}=88,8 \%$, o que indica que três medições são necessárias para predizer o valor real dessa variável.

Em geral, os coeficientes de repetibilidade e de determinação para as características morfofisiológicas indicaram confiabilidade na estimativa do número de observações necessárias para predizer o valor real das variáveis resposta, nos dois períodos de avaliação (Tabela 1). Para AF e TAF, os números de medições necessárias para predizer o valor real delas $\left(\mathrm{R}^{2}=80 \%\right)$ superou o número de ciclos avaliados, de maneira que, para estimativas confiáveis, é necessário um número mínimo de oito e sete avaliações para os ciclos curtos e longos, respectivamente (Tabela 1).

De acordo com Cruz \& Regazzi (1997), caracteres de baixa repetibilidade, com forte variação causada pelo ambiente, geralmente necessitam de elevado número de medidas para predição de seu valor genotípico real, como foi observado para as variáveis AF e TAF.

Daher et al. (2004) também utilizaram o método dos componentes principais, para estimar os coeficientes de repetibilidade e determinação de caracteres forrageiros em clones de capim-elefante de porte alto, e obtiveram, para altura média de planta, $\mathrm{r}=0,53 \mathrm{e}$ $\mathrm{R}^{2}=93 \%$. Os autores reportaram que quatro medições de altura de capim-elefante foram suficientes para se obter coeficiente de determinação acima de $80 \%$, o que confirma que, independentemente do porte, medidas confiáveis de altura média de plantas são obtidas com um número de avaliações reduzido.

A única variável que exigiu número de avaliações acima de cinco foi AFM, nos ciclos curtos, com sete avaliações $\left(\mathrm{R}^{2}=80 \%\right)$. No entanto, nos ciclos longos apenas duas avaliações foram suficientes para atingir esse mesmo coeficiente de determinação.

Para IAF e IL, os valores estimados para $\mathrm{r}, \mathrm{R}^{2} \mathrm{e}$ número de medições foram superiores nos ciclos longos (Tabela 1). Alguns autores (Falconer, 1981; Cruz \& Regazzi, 1997) afirmam que as estimativas de repetibilidade variam de acordo com a natureza da característica, com as propriedades genéticas da população e com as condições sob as quais os indivíduos são mantidos. Desse modo, os diferentes períodos de descanso das pastagens possivelmente influenciaram a quantidade de avaliações necessárias para predizer o valor real de IAF, AFM e IL. Nos ciclos de maior período de descanso das pastagens, as análises indicaram a necessidade de apenas uma avaliação $\left(\mathrm{R}^{2}=80 \%\right)$ para predição do valor real de IAF e IL. Nos ciclos de menor período de descanso, são necessárias cinco e quatro medições, respectivamente, para IAF e IL.

$\mathrm{Na}$ análise das variáveis morfofisiológicas pelo modelo de medidas repetidas no tempo, foi observado que as médias das alturas dos clones, no pré-pastejo, variaram entre 52,5 e 112,2 $\mathrm{cm}$ para o clone Taiwan A-146 2.37 (ciclo três) e para o Merker México MX 6.31 (quarto ciclo), respectivamente (Tabela 2). Diferenças significativas entre as médias dos clones só foram observadas nos ciclos curtos, tendo-se destacado, de maneira geral, o clone Taiwan-146 2.114 com os

Tabela 1. Estimativas dos coeficientes de repetibilidade $(\mathrm{r})$ e de determinação $\left(\mathrm{R}^{2}\right)$ e do número de medições necessárias, com coeficiente de determinação pré-estabelecido $\left(\mathrm{R}^{2}=80 \%\right)$ das variáveis morfofisiológicas e produtivas de capim-elefante de porte baixo sob pastejo de ovinos, em Itambé, PE.

\begin{tabular}{|c|c|c|c|c|c|c|c|c|c|}
\hline Ciclo de pastejo & $\mathrm{r}$ & $\mathrm{R}^{2}(\%)$ & Número de medições & $\mathrm{r}$ & $\mathrm{R}^{2}(\%)$ & Número de medições & $\mathrm{r}$ & $\mathrm{R}^{2}(\%)$ & Número de medições \\
\hline & \multicolumn{3}{|c|}{ Altura média de plantas } & \multicolumn{3}{|c|}{ Interceptação luminosa } & \multicolumn{3}{|c|}{ Índice de área foliar } \\
\hline 1,2 e 5 & 0,80 & 92,6 & 1 & 0,66 & 86,5 & 4 & 0,69 & 87,2 & 5 \\
\hline \multirow[t]{2}{*}{3 e 4} & 0,80 & 88,8 & 3 & 0,84 & 91,2 & 1 & 0,88 & 93,9 & 1 \\
\hline & \multicolumn{3}{|c|}{ Ângulo foliar médio } & \multicolumn{3}{|c|}{ Acúmulo de forragem } & \multicolumn{3}{|c|}{ Taxa de acúmulo de forragem } \\
\hline 1,2 e 5 & 0,72 & 88,1 & 7 & 0,38 & 65,51 & 8 & 0,39 & 65,52 & 8 \\
\hline 3 e 4 & 0,90 & 95,0 & 2 & 0,92 & 95,97 & 7 & 0,93 & 95,97 & 7 \\
\hline
\end{tabular}


maiores valores, e os clones Mott e Taiwan A-146 2.37 com os menores.

As variações observadas nas médias de altura de plantas, entre os ciclos de pastejo, foram proporcionais às variações ocorridas nas precipitações acumuladas para cada ciclo. Esse comportamento pode ser atribuído ao maior crescimento das plantas com maior disponibilidade de água no solo, desde que outros fatores ambientais, como temperatura e fotoperíodo, não sejam limitantes.

A precipitação acumulada no ciclo de pastejo quatro foi elevada, apesar de este ter sido considerado como seco (maior período de descanso). Isto foi causado pela baixa precipitação nos primeiros 32 dias de rebrota, com aumento acentuado da precipitação a partir daí, o que explica maiores médias de altura de plantas nos clones avaliados.

Foi observada a relação $\left(\mathrm{R}^{2}=62 \%\right)$ entre altura média do dossel e IL (Figura 1). O aumento na altura média do pasto causou aumentos da IL do dossel, com valores de IL próximos de 95\% (IAF crítico), correspondentes a alturas médias de $95 \mathrm{~cm}$. Fagundes et al. (2001) avaliaram diferentes cultivares de Cynodon sp. e relataram que pastos mantidos mais altos apresentam maiores valores de IL, independentemente da época do ano e da intensidade de pastejo. Ao avaliar respostas morfofisiológicas do capim Tanzânia à intensidade de pastejo, Mello \& Pedreira (2004) observaram aumentos exponenciais crescentes da IL até valores próximos de $95 \%$, com valores de altura média do dossel em torno de $55 \mathrm{~cm}$. Baseado nessa relação, Silva \& Pedreira (1997) consideram a altura do dossel como critério confiável para determinação do momento apropriado para a utilização da pastagem.

Tabela 2. Altura média de plantas $(\mathrm{cm})$ no pré-pastejo, em pastagens de capim-elefante de porte baixo, em cinco ciclos de pastejo (1ำ $2^{\circ}$ e $5^{\circ}-32$ dias de diferimento; $3^{\circ}$ e $4^{\circ}-64$ dias de diferimento) de pastejo de ovinos, em Itambé, $\mathrm{PE}^{(1)}$.

\begin{tabular}{llcccc}
\hline Genótipo & \multicolumn{5}{c}{ Ciclo de pastejo } \\
\cline { 2 - 6 } & $1^{\underline{0}}$ & $2^{\underline{0}}$ & $3^{\mathrm{o}}$ & $4^{\underline{0}}$ & $5^{\mathrm{o}}$ \\
\hline Taiwan A-146 2.27 & $72,0 \mathrm{ab}$ & $70,5 \mathrm{~b}$ & $57,0 \mathrm{a}$ & $91,7 \mathrm{a}$ & $77,0 \mathrm{ab}$ \\
Taiwan A-146 2.37 & $86,0 \mathrm{ab}$ & $67,2 \mathrm{~b}$ & $52,5 \mathrm{a}$ & $106,5 \mathrm{a}$ & $62,5 \mathrm{~b}$ \\
Taiwan-146 2.114 & $92,7 \mathrm{a}$ & $93,0 \mathrm{a}$ & $62,7 \mathrm{a}$ & $100,0 \mathrm{a}$ & $76,0 \mathrm{ab}$ \\
Merker México MX 6.31 & $84,5 \mathrm{ab}$ & $88,2 \mathrm{a}$ & $58,5 \mathrm{a}$ & $112,2 \mathrm{a}$ & $88,0 \mathrm{a}$ \\
Mott & $65,5 \mathrm{~b}$ & $65,5 \mathrm{~b}$ & $53,5 \mathrm{a}$ & $93,5 \mathrm{a}$ & $69,0 \mathrm{ab}$ \\
\hline CV (\%) & 13,83 & 8,99 & 13,26 & 11,73 & 11,53 \\
\hline Precipitação acumulada (mm) & 293,2 & 22,4 & 18,4 & 300,2 & 109,6 \\
\hline (1) Médias seguidas por letras iguais, nas colunas, não diferem entre si pelo \\
teste de Tukey, a 5\% de probabilidade.
\end{tabular}

Para o IAF no pré-pastejo, foram observadas diferenças $(\mathrm{p}<0,05)$ entre as médias dos clones, em todos os ciclos de pastejo, em que se destacaram, de maneira geral, os clones Taiwan A-146 2.114, com os maiores valores, e Taiwan A-1462.37, com os menores. No primeiro e quarto ciclos de pastejo, os genótipos apresentaram os maiores valores de IAF, com médias dos clones de 3,51 e 3,57, respectivamente. No ciclo três, foi observado o menor valor médio de IAF para os clones $(1,21)$. Os valores médios de IAF sofreram forte influência das precipitações acumuladas ao longo dos ciclos de pastejo (Figura 2). Este comportamento foi semelhante ao da altura média de plantas, e a variação para os valores médios mostrou relação com o ciclo de pastejo, traduzida principalmente pelos diferentes valores de precipitação acumulada. Esses dados estão de acordo com os de diversos autores (Gomide, 1973; Lemaire, 1997; Silva et al., 2002), que afirmam que o IAF é determinado pelas condições do ambiente, que influenciam diretamente as características estruturais do dossel durante o crescimento. Entre os cinco clones avaliados, apenas o Taiwan A-146 2.114 e o Mott atingiram valores de IAF crítico $(95 \%$ de IL) no pré-pastejo. Os valores observados foram 4,11 (95,3\% IL) para o Taiwan A -146 2.114, e 3,86 (95,2\% IL) para a cultivar Mott, observados no quarto ciclo de pastejo.

Valores de IAF crítico, aproximados ao do presente trabalho, foram relatados por Mello \& Pedreira (2004), que avaliaram pastagens de capim Tanzânia (Panicum

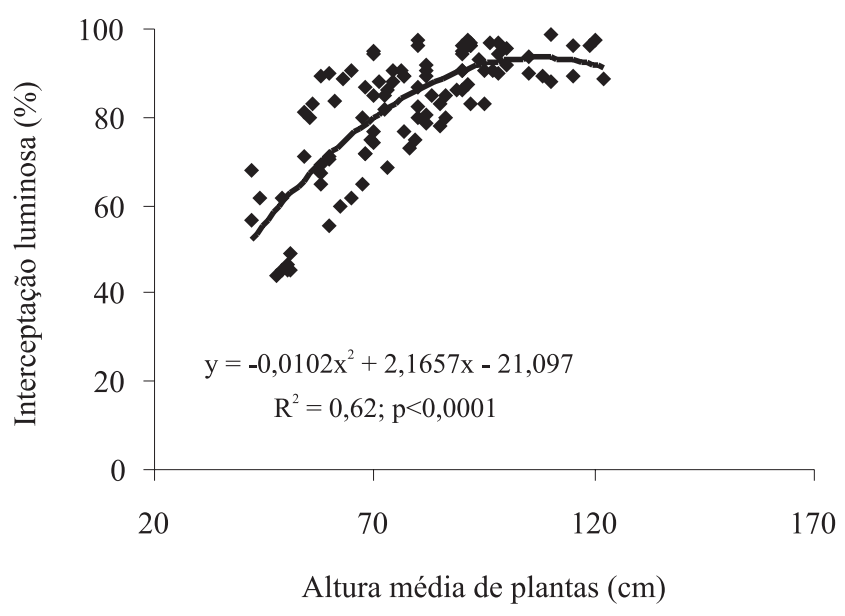

Figura 1. Relação entre interceptação luminosa e altura média de plantas, em pastagens de capim-elefante de porte baixo, ao longo de cinco ciclos de pastejo de ovinos. 
maximum Jacq.), em resposta a diferentes intensidades de desfolha, sob lotação animal intermitente, e com uso de irrigação. Os autores relataram valores de IAF crítico de 4,5 (97,1\% IL), 4 (96,1\% IL) e 3,6 (94,6\% IL), para intensidades de pastejo crescentes. O uso do IAF crítico, como critério para a entrada dos animais no pasto, com vistas ao aproveitamento máximo das taxas líquidas de fotossíntese do dossel, foi recomendado por Silva \& Nascimento Júnior (2006) e Curcelli (2009). Sua importância se deve ao fato de que valores de IAF com correspondente IL acima de $95 \%$ provavelmente reduzem as taxas de acúmulo de forragem, em virtude da redução do balanço líquido de carbono, decorrente do sombreamento das folhas inferiores pelas superiores, o que resulta na elevação das taxas respiratórias (Brown \& Blaser, 1968).

Existe forte relação $\left(\mathrm{R}^{2}=97 \%\right)$ entre IAF e IL no pré-pastejo (Figura 3). Esse comportamento é relatado na literatura (Brown \& Blaser, 1968; Fagundes et al., 2001; Mello \& Pedreira, 2004). Carvalho et al. (2007) avaliaram os efeitos de 50 e $100 \mathrm{~cm}$ de altura do resíduo em pastos de capim-elefante cv. Napier, durante seis ciclos de pastejo e também encontraram relação alta $\left(\mathrm{R}^{2}=99 \%\right) \mathrm{e}$ significativa $(p=0,0525)$ entre os valores médios de IAF e IL em três ciclos de pastejo. Assim como para outras espécies de plantas forrageiras, para capim-elefante de porte baixo, variações na IL do dossel são decorrentes das variações na área foliar, e são maiores quanto maiores forem os valores de IAF do dossel forrageiro.

Para os valores dos ângulos foliares médios (AFM), foram observadas diferenças entre os genótipos apenas no quarto e quinto ciclos de pastejo (Tabela 3 ). No quarto ciclo, verificou-se que os clones Taiwan A-146 2.114 e Mott apresentaram valores médios inferiores aos dos clones Taiwan A-146 2.27 e Taiwan A-146 2.37, e não diferiram dos valores da cultivar Merker México MX 6.31. No quinto ciclo, o valor da AFM do clone Mott foi superado apenas pelo da Taiwan A-146 2.27 e não diferiu dos demais. A partir do quarto ciclo, os clones Taiwan A-146 2.114 e Mott apresentaram folhas mais planas, enquanto os clones Taiwan A-146 2.27 e 2.37 apresentaram folhas mais erectófilas.

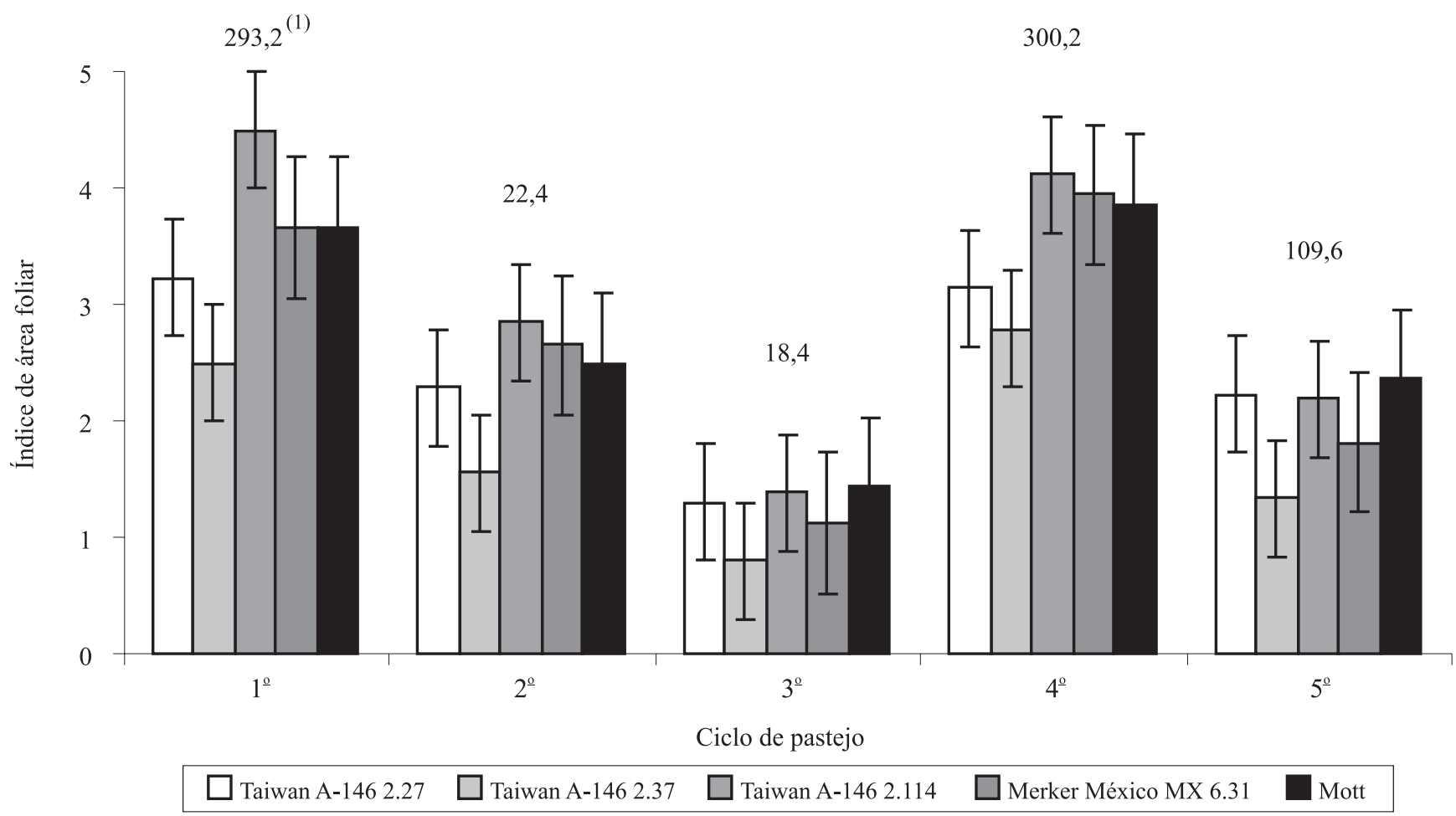

Figura 2. Índice de área foliar (IAF) no pré-pastejo, em pastagens de cinco genótipos de capim-elefante de porte baixo, ao longo de cinco ciclos (1ำ $2^{\circ}$ e $5^{\circ}-32$ dias de diferimento; $3^{\circ}$ e $4^{\circ}-64$ dias de diferimento) de pastejo por ovinos. ${ }^{(1)}$ Precipitação acumulada no período ( $\mathrm{mm})$. 
Diferenças nos ângulos de inserção entre e dentro de espécies forrageiras devem-se a algumas características como tamanho, peso e rigidez das folhas, que podem afetar sua estrutura e, consequentemente, o IAF crítico, a IL e o acúmulo de massa de matéria seca (Pedreira et al., 2001). Assim, apesar de terem sido observadas diferenças nos valores de AFM entre os genótipos, nos dois últimos ciclos de pastejo, essas respostas podem ter sido mais relacionadas às características inerentes a cada genótipo do que às condições ambientais entre os períodos, como relatado para as demais variáveis avaliadas.

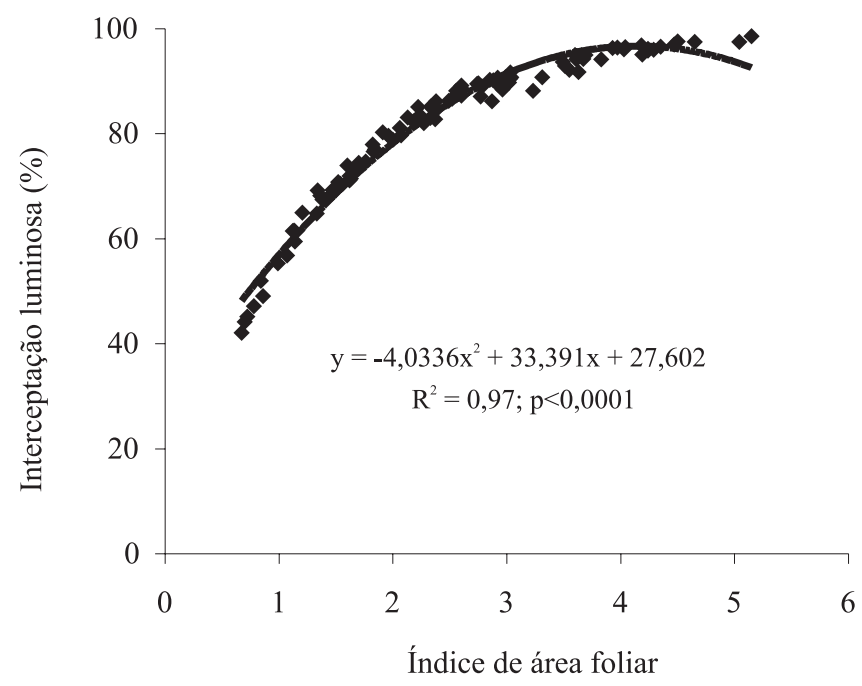

Figura 3. Relação entre a interceptação luminosa e o índice de área foliar (IAF) no pré-pastejo, em pastagens de capim-elefante de porte baixo, ao longo de cinco ciclos de pastejo.

Tabela 3. Ângulo foliar médio $\left(^{\circ}\right)$ de pastagens de capim-elefante de porte baixo em cinco ciclos (1으 $2^{\circ}$ e $5^{\circ}-$ 32 dias de diferimento; $3^{\circ}$ e $4^{\circ}-64$ dias de diferimento) sob pastejo de ovinos em Itambé, $\mathrm{PE}^{(1)}$.

\begin{tabular}{lccccc}
\hline Genótipo & \multicolumn{5}{c}{ Ciclo de pastejo } \\
\cline { 2 - 6 } & $1^{\underline{0}}$ & $2^{\mathrm{o}}$ & $3^{\mathrm{o}}$ & $4^{\mathrm{o}}$ & $5^{\mathrm{o}}$ \\
\hline Taiwan A-146 2.27 & $45,75 \mathrm{a}$ & $49,50 \mathrm{a}$ & $55,25 \mathrm{a}$ & $57,00 \mathrm{a}$ & $46,75 \mathrm{a}$ \\
Taiwan A-146 2.37 & $51,00 \mathrm{a}$ & $50,75 \mathrm{a}$ & $55,50 \mathrm{a}$ & $56,00 \mathrm{a}$ & $42,25 \mathrm{ab}$ \\
Taiwan-146 2.114 & $46,00 \mathrm{a}$ & $45,25 \mathrm{a}$ & $50,50 \mathrm{a}$ & $44,00 \mathrm{~b}$ & $42,75 \mathrm{ab}$ \\
Merker México MX 6.31 & $44,25 \mathrm{a}$ & $52,50 \mathrm{a}$ & $52,50 \mathrm{a}$ & $51,50 \mathrm{ab}$ & $44,00 \mathrm{ab}$ \\
Mott & $43,25 \mathrm{a}$ & $45,50 \mathrm{a}$ & $49,50 \mathrm{a}$ & $47,25 \mathrm{~b}$ & $39,25 \mathrm{~b}$ \\
\hline CV (\%) & 8,43 & 9,91 & 10,54 & 7,29 & 4,94 \\
\hline
\end{tabular}

${ }^{(1)}$ Médias seguidas por letras iguais na coluna não diferem entre si pelo teste de Tukey, a $5 \%$ de probabilidade.

\section{Conclusões}

1. Em clones de capim-elefante de porte baixo sob pastejo de ovinos é possível, com apenas uma avaliação, predizer o valor genotípico $\left(\mathrm{R}^{2}=80 \%\right)$ do índice de área foliar e da interceptação luminosa, nos ciclos curtos de 32 dias, e a altura média de plantas, nos ciclos longos de 64 dias.

2. Em clones de capim-elefante de porte baixo sob pastejo de ovinos, a obtenção de estimativas confiáveis do aumento e da taxa de aumento de forragem, exige períodos experimentais mais longos e com maior número de ciclos de pastejo.

3. O índice de área foliar, a interceptação luminosa e a altura média das plantas dos genótipos de capim-elefante de porte baixo estão sujeitos a efeitos marcantes das precipitações pluviais acumuladas ao longo dos ciclos de pastejo.

4. Em dosséis de capim-elefante de porte baixo, a interceptação da radiação incidente é diretamente proporcional à altura média das plantas e ao índice de área foliar.

\section{Agradecimentos}

Ao Conselho Nacional de Pesquisa e Desenvolvimento, pelas bolsas de pesquisa; ao Banco do Nordeste do Brasil, à Fundação de Amparo à Ciência e à Tecnologia do Estado de Pernambuco e ao Programa de Apoio ao Desenvolvimento Sustentável da Zona da Mata de Pernanbuco, pelo apoio financeiro; à Universidade Federal de Pernambuco e ao Instituto Agronômico de Pernambuco, pelo acordo firmado para a realização do trabalho.

\section{Referências}

ALMEIDA, E.X. de; MARASCHIN, G.E.; HARTHMANN, O.E.L.; RIBEIRO FILHO, H.M.N.; SETELICH, E.A. Oferta de forragem de capim-elefante anão 'Mott' e a dinâmica da pastagem. Revista Brasileira de Zootecnia, v.29, p.1281-1287, 2000a.

ALMEIDA, E.X. de; MARASCHIN, G.E.; HARTHMANN, O.E.L.; RIBEIRO FILHO, H.M.N.; SETELICH, E.A. Oferta de forragem de capim-elefante anão 'Mott' e o rendimento animal. Revista Brasileira de Zootecnia, v.29, p.1295-2000, 2000 b.

BROWN, R.H.; BLASER, R.E. Leaf area index in pasture growth. Herbage Abstracts, v.38, p.1-19, 1968.

CAMPOS, R.T. Uma abordagem econométrica do mercado potencial de carne de ovinos e caprinos para o Brasil. Revista Econômica do Nordeste, v.30, p.26-47, 1999.

CARVALHO, C.A.B. de; ROSSIELLO, R.O.P.; PACIULLO, D.S.C.; SBRISSIA, A.F.; DERESZ, F. Classes de perfilhos na composição 
do índice de área foliar em pastos de capim-elefante. Pesquisa Agropecuária Brasileira, v.42, p.557-563, 2007.

CRUZ, C.D. Programa GENES: aplicativo computacional em genética e estatística. Viçosa: UFV, 2007. 442p.

CRUZ, C.D.; REGAZZI, A.J. Modelos biométricos aplicados ao melhoramento genético. 2.ed. Viçosa: UFV, 1997. 390p.

CURCELLI, F. Respostas morfogênicas e dinâmica de acúmulo de forragem do capim- xaraés [Brachiara bizantta (A. Rich.) Stapf. cv. Xaraés] submetidos a estratégias de pastejo rotativo. 2009. 90p. Dissertação (Mestrado) - Escola Superior de Agricultura Luiz de Queiroz, Piracicaba.

DAHER, R.F.; MALDONADO, H.; PEREIRA, A.V.; AMARAL JUNIOR, A.T. do; PEREIRA, M.G.; FERREIRA, C.F.; RAMOS, S.R.R; TARDIN, F.D.; SILVA, M.P. da. Estimativas de parâmetros genéticos e de coeficientes de repetibilidade de caracteres forrageiros em clones de capim-elefante (Pennisetum purpureum Schum.). Acta Scientiarum. Agronomy, v.26, p.483-490, 2004.

FAGUNDES, J.L.; SILVA, S.C. da; PEDREIRA, C.G.S.; CARNEVALLI, R.A.; CARVALHO, C.A.B. de; SBRISSIA, A.F.; PINTO, L.F. de M. Índice de área foliar, coeficiente de extinção luminosa e acúmulo de forragem em pastagens de Cynodon spp. sob lotação contínua. Pesquisa Agropecuária Brasileira, v.36, p.187-195, 2001.

FALCONER, D.S. Introdução à genética quantitativa. Viçosa: UFV, 1981.279p.

FLORES, J.A.; MOORE, J.E.; SOLLENBERGER, L.E. Determinants of forage quality in Pensacola bahiagrass and Mott elephantgrass. Journal of Animal Science, v.71, p.1606-1614, 1993.

GOMIDE, J.A. Fisiologia do crescimento livre de plantas forrageiras. In: SIMPÓSIO SOBRE MANEJO DAPASTAGEM, 1973, Piracicaba. Anais. Piracicaba: FEALQ, 1973. p.83-93.

GOVERNO DE PERNAMBUCO. Secretaria de Ciência, Tecnologia e Meio Ambiente. Companhia Pernambucana do Meio Ambiente. Diagnóstico socioambiental do litoral norte de Pernambuco. Recife: CPRH, 2003. 214p.

JACQUES, A.V.A. Caracteres morfo-fisiológicos e suas implicações com o manejo. In: CARVALHO, M.M.; ALVIN, M.J.; XAVIER, D.F.; CARVALHO, L. de A. (Ed.) Capim-elefante: produção e utilização. Coronel Pacheco: Embrapa-CNPGL, 1994. p.31-48.

LÉDO, F.J. da S.; PEREIRA, A.V.; SOUZA SOBRINHO, F. de; AUAD, A.M.; JANK, L.; OLIVEIRA, J.S. e. Estimativas de repetibilidade para caracteres forrageiros em Panicum maximum. Ciência e Agrotecnologia, v.32, p.1299-1303, 2008.

LEMAIRE, G. The physiology of grass growth under grazing: tissue turnover. In: SIMPÓSIO INTERNACIONAL SOBRE PRODUÇÃO ANIMAL EM PASTEJO, 1997, Viçosa. Anais. Viçosa: UFV, 1997. p.117-144.

MAUCHLY, J.W. Significance test for sphericity of a normal n-variate distribution. The Annals of Mathematical Statistics, v.11, p.204-209, 1940.

MELLO, A.C.L. de; PEDREIRA, C.G.S. Respostas morfológicas do capim-tanzânia (Panicum maximum Jacq. cv. Tanzânia-1) irrigado à intensidade de desfolha sob lotação rotacionada. Revista Brasileira de Zootecnia, v.33, p.282-289, 2004.

PEDREIRA, C.G.S.; MELLO, A.C.L.; OTANI, L. O processo de produção de forragem em pastagens. In: REUNIÃO ANUAL DA SOCIEDADE BRASILEIRADE ZOOTECNIA, 38., 2001, Piracicaba. Anais. Piracicaba: FEALQ, 2001. p.772-807.

PEREIRA, A.V.; CRUZ, C.D.; FERREIRA, R. de P.; BOTRELL, M. de A.; OLIVEIRA, J.S. e. Influência da estabilização de genótipos de capim-elefante (Pennisetum purpureum Schum.) sobre a estimativa da repetibilidade de características forrageiras. Ciência e Agrotecnologia, v.26, p.762-767, 2002.

RESENDE, K.T. de; MEDEIROS, A.N. de; PEREIRA FILHO, J.M.; YÁÑEZ, E.A.; TEIXEIRA, I.A.M. de A.; FREGADOLLI, F.L. Produção de leite de cabras em regime de pasto. In: SEMINÁRIO NORDESTINO DE PECUÁRIA, 6., 2002, Fortaleza. Anais. Fortaleza: SEBRAE, 2002. p.203-215.

SANTOS, H.G. dos; JACOMINE, P.K.T.; ANJOS, L.H.C. dos; OLIVEIRA, V.A. de; OLIVEIRA, J.B. de; COELHO, M.R.; LUMBRERAS, J.F.; CUNHA, T.J.F. (Ed.). Sistema brasileiro de classificação de solos. 2.ed. Rio de Janeiro: Embrapa Solos, 2006. $306 \mathrm{p}$.

SAS INSTITUTE. SAS/STAT user's guide. Version 9.1 Cary: SAS Institute, 2001.

SHIMOYA, A.; CRUZ, C.D.; FERREIRA, R. de P.; PEREIRA, A.V.; CARNEIRO, P.C.S. Divergência genética entre acessos de um banco de germoplasma de capim-elefante. Pesquisa Agropecuária Brasileira, v.37, p.971-980, 2002.

SILVA M.M.P. da; VASQUEZ, H.M.; SILVA, J.F.C. da; BRESSAN-SMITH, R.E.; ERBESDOBLER, E.D'A.; SOARES, C. da S. Composição bromatológica, disponibilidade de forragem e índice de área foliar de 17 genótipos de capim-elefante (Pennisetum purpureum Schum.) sob pastejo, em Campos dos Goytacazes, RJ. Revista Brasileira de Zootecnia, v.31, p.313-320, 2002.

SILVA, D.S.; GOMIDE, J.A.; QUEIROZ, A.C. Pressão de pastejo em pastagem de capim-elefante anão (Pennisetum purpureum Schum. cv. Mott). 2. Efeito sobre o valor nutritivo, consumo de pasto e produção de leite. Revista Brasileira de Zootecnia, v.23, p.453-464, 1994.

SILVA, S.C. da; NASCIMENTO JÚNIOR, D. do. Ecofisiologia de plantas forrageiras. In: SIMPÓSIO SOBREMANEJOESTRATÉGICO DA PASTAGEM, 3., 2006, Viçosa. Anais. Viçosa: UFV, 2006. p.1-42.

SILVA, S.C. da; PEDREIRA, C.G.S. Princípios de ecologia aplicados ao manejo da pastagem. In: SIMPÓSIO SOBRE ECOSSISTEMAS DE PASTAGENS, 3., 1997, Jaboticabal. Anais. Jaboticabal: Funep, 1997. p.1-12.

VIEIRA, F.T.P. de A.; SILVA, J.A.A. da; FERREIRA, R.L.C.; CRUZ, M.A.O.M. da; FERRAZ, I. Uma abordagem multivariada em experimento silvipastoril com Leucaena leucocephala (Lam.) de Wit no Agreste de Pernambuco. Ciência Florestal, v.17, p.333-342, 2007.

WELLES, J.M.; NORMAN, J.M. Instrument for indirect measurement of canopy architecture. Agronomy Journal, v.83, p.818-825, 1991.

Recebido em 31 de julho de 2009 e aprovado em 26 de novembro de 2009 